\author{
Xinkuan Yan \\ Chaohe Chen \\ Tianhui Fan*
}

http://dx.doi.org/10.21278/brod69206

ISSN 0007-215X

eISSN 1845-5859

\title{
EFFECTS OF DIFFERENT WAVE SPECTRA ON DYNAMIC POSITIONING ACCURACY
}

UDC 629.5.016.8:629.563

Professional paper

\begin{abstract}
Summary
To achieve high accuracy of positioning method for ships which have good mobility and are uninfluenced by the water depth, the dynamic positioning system has come into being. More and more ships working in deepwater area tend to install dynamic positioning system. The main objective of this study is to discuss the effects of different wave spectra on the dynamic positioning accuracy. First, considering some parameters of a certain dynamic positioning ship, the Response Amplitude Operator (RAO) is calculated by AQWA. Then, time domain simulations and calculations for the ship motion have been conducted by OrcaFlex based on JONSWAP, ISSC, Ochi-Hubble, Torsethaugen and Gaussian Swell, respectively. Finally, the analysis results are compared to discuss the dynamic positioning accuracy. Some useful conclusions and recommendations are obtained to lay a theoretical foundation of actual project practice.
\end{abstract}

Key words: $\quad$ dynamic positioning; wave spectra; numerical simulation; time-domain analysis;

\section{Introduction}

With the global energy shortage, the exploitation of oil in deep seas are increasing. At present, the development trend of offshore oil and gas resources is also developed from shallow water to deep water. The development of marine resources and marine high technology has become an inevitable tendency for the utilization of ocean energy resources. Ships and other floating facilities usually need to be located at a particular position in the sea for various operations. The traditional mooring positioning method is simple and economical, but it has low positioning accuracy and poor maneuverability. Once anchored, the process of repositioning is more complicated [1]. That is to say, the traditional mooring positioning can not meet the requirements of some marine operations.

In order to meet higher requirements of ocean engineering operations and to keep their position and heading in the ocean, ships equipped with a dynamic positioning system has come into being [2]. The dynamic positioning system refers to the closed-loop control system which is used to measure the deviation of the actual course, position and target course and position of the ship; by taking into account the influence of environmental interference such 
as waves, the dynamic positioning system can calculate the thrust load required to return to the target course and position to keep the ship at the target heading and position [3].

The dynamic coupling analysis is recognized as the most reliable numerical method presently and an accurate computational analysis of wave-body interaction is important in the design of marine vessels [4][5]. In order to study the effect of different wave spectra of ship dynamic positioning, the three-dimensional model is built and imported into AQWA to obtain Response Amplitude Operator(RAO), added mass and radiation damping response amplitude by frequency domain analysis. Then combined with the hydrodynamic software OrcaFlex, by changing the environmental parameters, the hydrodynamic response of the dynamic positioning ship under different wave spectra is analyzed. Finally, the influence of different wave spectra on the dynamic positioning accuracy of the DP ship has been obtained. The results have some guiding significance for the actual engineering practice.

\section{Wave spectra}

OrcaFlex provides regular and random waves. The regular wave theories include linear Airy and nonlinear wave theory, such as Stokes 5th order wave theory, cnoidal wave and Dean Stream. In order to describe the internal structure of random waves, standard wave frequency spectra are applied. According to Fourier analysis, the irregular wave could be decomposed into a number of waves with discrete frequencies, or a spectrum of frequencies over a continuous range. The statistical average of a certain irregular wave as analyzed in terms of its frequency content, is called its spectrum [6]. It is based on a large number of data observed by many researchers, analyzing various statistical values and spectral density of waves. Each wave spectrum is derived from the measurement, statistics and analysis in a specific condition and a specific sea area and has their own advantages and limitations. JONSWAP, ISSC, Ochi-Hubble, Torsethaugen and Gaussian Swell are used in this paper, there are berif introduction for them:

The JONSWAP spectrum in OrcaFlex is defined as:

$$
S(f)=\left(\alpha g^{2} / 16 \pi^{4}\right) f^{-5} \exp \left(-5 / 4\left[f / f_{m}\right]^{-4}\right) \gamma^{b}
$$

where $\alpha$ is a spectral energy parameter, $\mathrm{g}$ is the gravitational constant, $f_{m}$ is the spectral peak frequency, $\gamma$ is peak enhancement factor which have detailed description in relevant literature [7]. $b=\exp \left(-1 / 2^{-2}\left[f / f_{m}-1\right]^{2}\right), \sigma=\sigma_{1}$ for $f \leq f_{m}, \sigma=\sigma_{2}$ for $f>f_{m}, \sigma$ and $\sigma_{l}$ are spectral width parameters which are set at the standard values of 0.07 and 0.09 respectively. JONSWAP sprectrum is mainly used for describing no-full development wave and considers finite wind pressure.

The ISSC spectrum (modified Pierson-Moskowitz) is defined as:

$$
S(f)=5 / 16 H_{s}^{2} f_{m}^{4} f^{-5} \exp \left(-5 / 4\left[f / f_{m}\right]^{-4}\right)
$$

$H_{s}$ is significant wave height. For the ISSC spectrum you specify $H_{s}$ and $T_{z}$ and OrcaFlex calculates the other spectral parameter. More detail information can be seen in the reference [8].

The Ochi-Hubble Spectrum allows two peaked spectra to be set up, which shows sea states that include both a remotely generated swell and a local wind generated sea. The OchiHubble wave spectrum is the sum of two separate component spectra. The component spectrum with the lower frequency peak corresponds to the remotely generated swell and the one with the higher frequency peak corresponds to the local wind generated sea. This is why the Ochi-Hubble spectrum is often called a two-peaked spectrum; however in practice, the resulting total spectrum typically has only one peak (from the remotely generated swell) plus 
a shoulder of energy from the local wind generated sea. More details of the Ochi-Hubble Spectrum could be found in the reference [9].

The Torsethaugen spectrum is another two-peaked spectrum, more suited to North Sea application than Ochi-Hubble. More details of the Torsethaugen and Haver could be found in the reference [10].

The Gaussian Swell spectrum is based on the normal (or Gaussian) probability density function and is defined as:

$$
S(f)=\left(H_{s} / 4\right)^{2} \sigma^{-1}(2 \pi)^{-1 / 2} \exp \left(-\left[f-f_{m}\right]^{2}\right) / 2 \sigma^{2}
$$

$f_{m}=1 / T_{p}$, The Gaussian Swell spectrum is typically used to model long period swell seas.

Nonlinearity of the wave has an important effect on ship motion especially in the natural frequency region [11]. During numerical simulation, the calculation of transient wave forces in irregular waves refers to literature [12].

\section{Description of the dynamic positioning system}

OrcaFlex includes a well-documented programming interface called OrcFxAPI which is a windows dynamic link library(DLL). The OrcFxAPI is used to product the dynamic positioning system in our study. DLL provides facilities for setting data, calculating static positions and extracting results from those calculations or from pre-run simulation files [13]. It uses an external function in Python to keep the vessel on station by making the global applied force moment simply proportional to the difference between the actual and target position and heading of the vessel. This has the same effect as applying simple linear springs in the global X and Y-directions, and a torsional spring about the vertical. A real DP system would use multiple thrusters a more sophisticated controlling algorithm actually.

The magnitude of the heave, roll and pitch variables is relatively small, thus, the DP systems used in most of the industrial ship control systems do not consider the vertical motion [14]. In this study, only the horizontal motions are considered for the DP system. OrcFxAPI is chosen here to simulate the DP system for the ship. A global applied load is specified on the Applied Loads page of the DP Vessel data form. The load uses the external function variable data item called Thruster to calculate the components of applied force in the global $\mathrm{X}$ and $\mathrm{Y}$ directions, and the applied moment about the global $\mathrm{Z}$ direction (vertically upwards). On the Variable Data form, the Python module and class is specified for this Thruster variable data source. The target position and heading of the vessel, the control parameters of reaction and reaction torque, are specified on the External Functions page of the DP Vessel data form. Thruster Data can be saved in the model workspace dictionary. The governing equations of the DP system are shown as follows [15]:

$$
\begin{gathered}
F_{X}=\left(T_{X^{-}} v_{P}[0]\right) \cdot k_{f} \\
F_{Y}=\left(T_{Y^{-}} v_{P}[1]\right) \cdot k_{f} \\
M_{Z}=\left(T_{H^{-}} v_{h}\right) \cdot k_{m}
\end{gathered}
$$

In the above equations, $F_{X}, F_{Y}$ mean the thruster force in surge, sway direction, respectively; $M_{Z}$ is the thruster moment in row direction; $\mathrm{T}_{\mathrm{X}}, \mathrm{T}_{\mathrm{Y}}, \mathrm{T}_{\mathrm{H}}$ denote the target position of the vessel origin in $X, Y$ direction, and the heading angle of the vessel; $v_{P}, v_{h}$ represent the vessel instantaneous position in $X, Y$ drection and vessel heading angle, which can be calculated by OrcaFlex; $k_{f}, k_{m}$ show forces applied by thruster per unit distance away from the target position and moment per degree away from the target heading respectively. 


\section{Wave spectra frequency-domain hydrodynamic analysis}

In this work, the AQWA module is used to conduct the frequency-domain hydrodynamic analysis of the ship. First, the RAOs are obtained. Then the calculated data are imported into OrcaFlex. Finally, the dynamic response of dynamic positioning ship based on different wave spectra is made by changing the environment parameter.

\subsection{Establishment of ship model in AQWA}

Combined with the main dimensions and other parameters of a ship, the ship model is established in AQWA and the grids are made into some elements. The basic parameters of the ship are shown in Table 1.

The global coordinate system is defined as $\mathrm{O}-\mathrm{XYZ}$ and the ship coordinate system is defined as v-xyz, respectively. The motions of six degrees of freedom of the ship under the action of waves are three translational components (surge, sway, heave) along the $\mathrm{x}$-axis, the $y$-axis and the z-axis direction of the ship coordinate system v-xyz and three rotational components (roll, pitch and yaw) round the $\mathrm{x}$-axis the $\mathrm{y}$-axis and the $\mathrm{z}$-axis direction of the ship coordinate system v-xyz. The ship model established in AQWA has 17385 nodes and 17183 elements, the maximum element size is $1.5 \mathrm{~m}$, and the upper end of the range of the wave frequency is $0.457 \mathrm{~Hz}$. The ship is regarded as a whole in AQWA, and with a boundary element numerical method for solving the structure of wave loads and considering the 2 nd order wave force. In this paper, the ship modeling in AQWA is as follows.

Table 1 Basic parameters of the ship

\begin{tabular}{|c|c|c|c|c|}
\hline Length $(\mathrm{m})$ & $\operatorname{Beam}(\mathrm{m})$ & $\operatorname{Depth}(\mathrm{m})$ & $\operatorname{Draft}(\mathrm{m})$ & Displacement(ton) \\
\hline 207.21 & 36.03 & 16.16 & 10.00 & 57816.01 \\
\hline \multirow{2}{*}{$\begin{array}{l}\text { Waterplane Area } \\
\qquad\left(\mathrm{m}^{2}\right)\end{array}$} & \multicolumn{4}{|c|}{ Radius of Gyration(m) } \\
\hline & \multicolumn{2}{|l|}{$\mathrm{K}_{\mathrm{xx}}$} & $\mathrm{K}_{\mathrm{yy}}$ & $\mathrm{K}_{\mathrm{zz}}$ \\
\hline 6203.14 & \multicolumn{2}{|l|}{13.332} & 50.845 & 52.879 \\
\hline
\end{tabular}

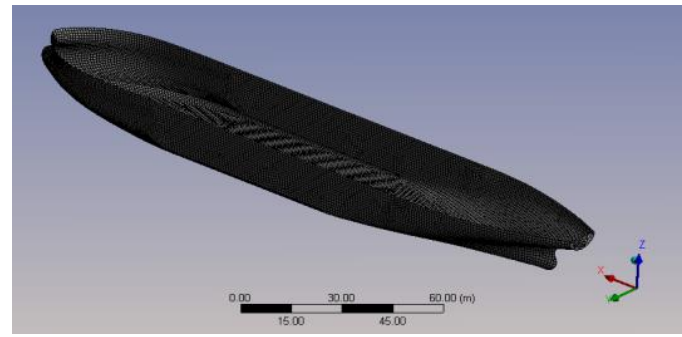

Fig. 1 Ship surface element model

\subsubsection{RAOs of the ship}

The ship model is imported into the AQWA and the relevant parameters are set up. The hydrodynamic parameters are shown in Table 2 . The wave frequency range is $0.01-0.457 \mathrm{~Hz}$, which covers the vast majority of the wave energy.

Table 2. Hydrodynamic analysis parameters

\begin{tabular}{|c|c|}
\hline Water Depth $/ \mathrm{m}$ & 200 \\
\hline Wave Directions $\alpha /{ }^{\circ}$ & $0^{\circ}-360^{\circ}\left(\right.$ interval $\left.22.5^{\circ}\right)$ \\
\hline Wave Frequencies $/ \mathrm{Hz}$ & $0.01-0.457($ interval 0.011$)$ \\
\hline Water Density $/ \mathrm{kg} \cdot \mathrm{m}^{-2}$ & 1025 \\
\hline
\end{tabular}


The RAOs of six degrees of freedom under different wave directions (surge, sway, heave, roll, pitch, and yaw) of the ship are obtained:

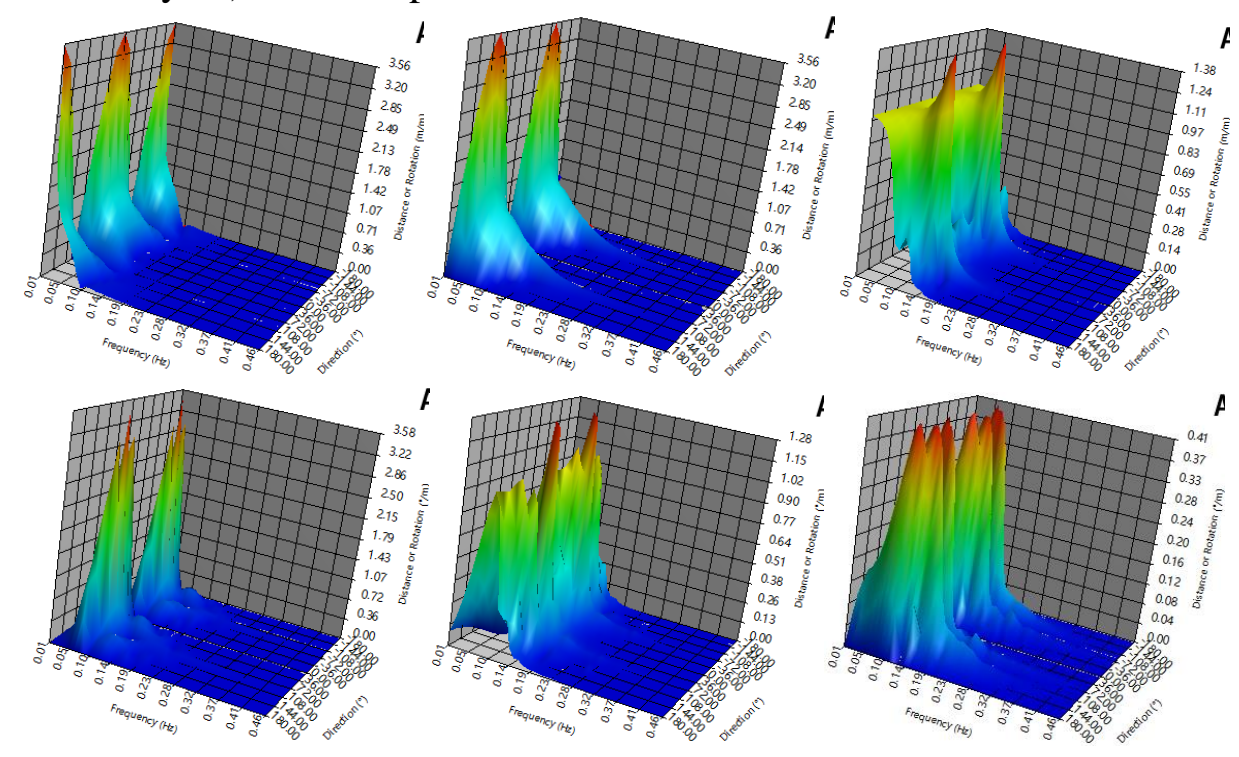

Fig. 2 Ship RAOs of different wave directions

It can be obtained from Figure 2 that in the $0^{\circ}-180^{\circ}$, when the wave frequency is very small, the surge RAOs under $0^{\circ}$ wave direction have a maximum value and there is a minimum value under $90^{\circ}$ wave direction for the surge RAOs; the results of the sway RAOs is contrary to that of the surge RAOs. When the frequency is in $0.01-0.05 \mathrm{~Hz}$, the values of the heave RAOs are basically same under each wave direction. From Figure 2, when the wave angle is $90^{\circ}$, the roll RAOs have the maximum value and there are two peaks around the maximum value; the pitch RAOs have the minimum value under $90^{\circ}$ wave direction; the minimum value of yaw RAOs appears under $0^{\circ}$ wave direction and the maximum value appears in the wave direction $45^{\circ}$ and $135^{\circ}$. At the same time, Most of the RAOs peaks occur in the low frequency phase, which are less than $0.3 \mathrm{~Hz}$; the same frequency, the same wave direction, pitch, yaw and roll have the larger RAOs value, that's way we focus on the three degrees of freedom ship motion response.

\section{Time domain analysis of ship motion}

Since the pioneering work by Cummins [16], Liapis and Beck [17] for time-domain methods, the time domain method in dealing with some of the seakeeping problems has gradually began to replace the frequency domain analysis. Thus, the nonlinear problem of the ship motions is usually solved by time-domain analysis.

Large structures on the sea surface will oscillate at a specific periodicity. These cycles do not have the influence of the first-order spectral energy, which are not for the action of the first-order wave forces. These periodic motions may cause large resonance motions in the water which is called the low-frequency motion. Although the structure will heave, roll and pitch in waves, we are more concerned about the motions in the horizontal plane: surge, sway and yaw. The equation for low-frequency motion can be expressed as [18]:

$$
\left[m_{s}+m_{a}\right] \ddot{x}(t)=F_{s v}(t)+F_{c}(t)+F_{w}(t)+F_{h}(t)+F_{d}(t)+F_{D P}(t)
$$

In the above formula, $\ddot{\mathrm{x}}$ is the acceleration vector; $m_{s}$ is the mass and inertia of the floating body; $m_{a}$ is added mass and inertia in low frequency; $F_{s v}$ is slow drift force; $F_{c}$ is 
current load; $F_{w}$ is wind load; $F_{h}$ is hydrostatic pressure; $F_{d}$ is damping force, $F_{D P}$ is thrust offered by propeller. constants.

In the process of calculation, the added mass, inertia and damping are considered as

\subsection{Setting of model parameters in OrcaFlex}

Ship model is built in OrcaFlex, and the ship-related parameters are imported from AQWA. The ship is equipped with dynamic positioning system (DP ship). In order to overcome the influence of the wind, wave, current and other environmental loads on the departure of ship from the course, the DP ship is driven by automatic control of the main propulsion, lateral thrust device, which make thrust and torque in actual construction process. The dynamic positioning effect of the ship depended on the programming module. When the environment parameters are input, the ship could get the opposite direction of the environment load force (moment) to make the ship position in the target position with small amplitude fluctuation.

For dynamic positioning vessel, only three degrees-of-freedom (sway, surge and sway) motions in the horizontal direction are considered. This is because the remaining three directions (heave, roll, pitch) have a certain restoring force (moment), can reset itself, which do not need to control.

In this paper, OrcaFlex is used to analyze the time domain of the ship equipped with dynamic positioning system. The whole process is divided into two stages: static stage and dynamic stage. The purpose of the static analysis is to determine the static equilibrium state of the whole operating system under the action of environmental load coupling. The system equilibrium achieved by static analysis provides the best initial state for dynamic analysis. The dynamic analysis is based on the static analysis results and it simulates the dynamic response of the ship under nonlinear wave loads.

The environmental parameters are set as follows: the average wave height is $6.2 \mathrm{~m}$, the spectrum peak period is $11.1 \mathrm{~s}$, the wind speed is $19.3 \mathrm{~m} / \mathrm{s}$, the surface current velocity is $1.1 \mathrm{~m} / \mathrm{s}$ and the wind direction is $90^{\circ}$. In this case, we use two coordinate systems, one is global coordinate system GXYZ, another is local systems Vxyz. All the coordinate systems are right-handed, as shown in the following figure. Directions for waves, current and wind are specified by giving the direction in which the wave (or current or wind) is progressing, relative to global axes. Both of initial position and target positin of this ship are set $X=120 \mathrm{~m}$, $\mathrm{Y}=80 \mathrm{~m}, \phi=90 \mathrm{deg}$, which are also relative to the global coordinate system.
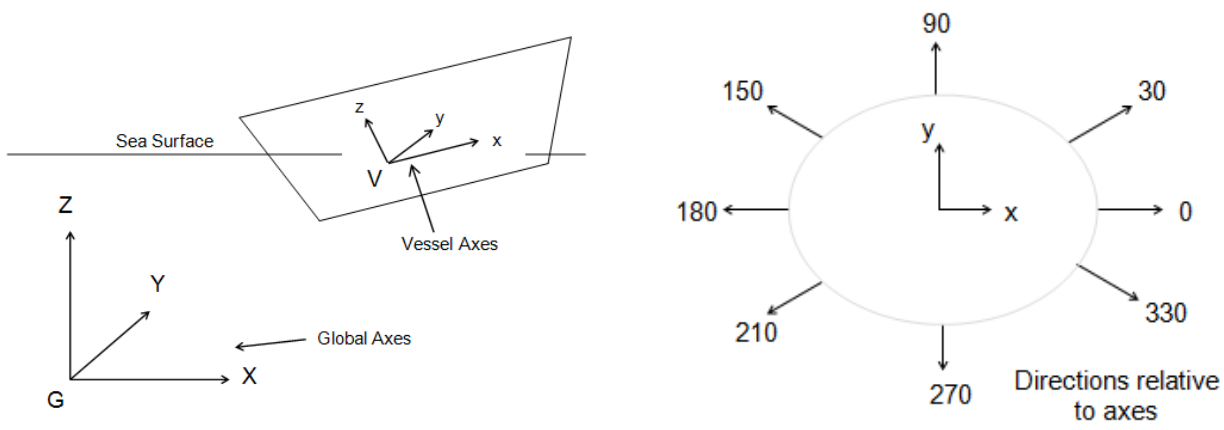

Fig.4 Coordinate Systems and the environment load directions

\subsection{Motion response of DP ship based on different wave spectra}

In order to analyse the effects of different wave spectra on DP ship, the steady-state time series of 2000s-4000s are chosen here. The statistical result is shown in Figure.5 and Table.3. 

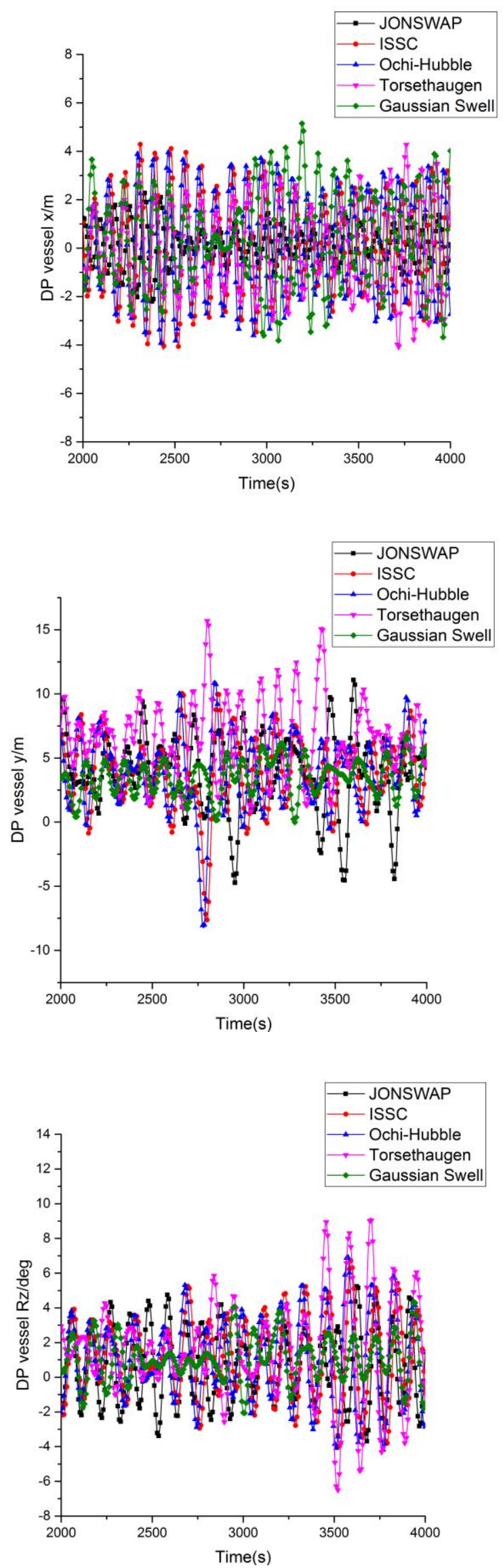

Fig. 5 Horizontal motion of DP ship 
It can be concluded from Figure 5 that the horizontal motion curves calculated by ISSC spectrum and Ochi-Hubble spectrum are in consistent. Other wave spectra have different effects on the calculations of DP ship's horizontal motion, which means dynamic positioning accuracy calculated by different wave spectra can be different. The same wave spectrum can induce different effect on different motion directions.

Table 3 The statistic of ship's horizontal motion

\begin{tabular}{|c|c|c|c|c|}
\hline $\begin{array}{c}\text { Wave } \\
\text { Spectrum }\end{array}$ & Horizontal Motion & Max & Mean & Standard Deviation \\
\hline \multirow{4}{*}{ JONSWAP } & Surge/m & 3.658 & 0.121 & 1.198 \\
\cline { 2 - 5 } & Sway/m & 11.184 & 3.934 & 2.721 \\
\cline { 2 - 5 } & Yaw/deg & 5.330 & 0.751 & 2.145 \\
\hline \multirow{4}{*}{ ISSC } & Surge/m & 4.287 & 0.127 & 2.074 \\
\cline { 2 - 5 } & Sway/m & 10.178 & 3.836 & 2.881 \\
\cline { 2 - 5 } & Yaw/deg & 6.715 & 1.089 & 2.332 \\
\hline \multirow{3}{*}{ Ochi-Hubble } & Surge/m & 3.996 & 0.118 & 1.989 \\
\cline { 2 - 5 } & Sway/m & 10.952 & 3.741 & 3.212 \\
\cline { 2 - 5 } Torsethaugen & Yaw/deg & 7.006 & 1.081 & 2.445 \\
\cline { 2 - 5 } & Surge/m & 4.286 & 0.059 & 1.743 \\
\cline { 2 - 5 } & Sway/m & 15.790 & 6.540 & 2.723 \\
\hline \multirow{3}{*}{ Gaussian Swell } & Yaw/deg & 9.187 & 1.466 & 2.643 \\
\cline { 2 - 5 } & Surge/m & 6.868 & 0.495 & 2.124 \\
\cline { 2 - 5 } & Sway/m & 6.751 & 3.282 & 1.507 \\
\hline & Yaw/deg & 4.684 & 1.025 & 1.451 \\
\hline
\end{tabular}

According to the table.3, the maximum and standard deviation of DP ship's displacement amplitude in surge direction calculated by JONSWAP spectrum are the smallest. In all wave spectra, the maximum, mean and standard deviation of ship's surge calculated by Gaussian Swell spectrum are highest, which shows that the ship's surge motion can be change rapidly and the dynamic positioning accuracy of longitudinal direction is worst. The displacement amplitude of the DP ship in the sway direction is larger than that in the surge direction. Although the maximum and mean calculated by Torsethaugen spectrum are high, the standard deviation is not very large. That shows the ship's sway amplitude calculated by this way is high but not change rapidly, the maximum, mean and standard deviation calculated by Gaussian Swell spectrum are lowest, which proves that the dynamic positioning accuracy of sway direction is good. Besides, the maximum, mean and standard deviation calculated by Torsethaugen spectrum in yaw direction are highest, so the dynamic positioning accuracy is the worst while that calculated by Gaussian Swell spectrum is best. The statistic in three directions calculated by ISSC spectrum and Hubble spectrum are almost the same, which means the dynamic positioning accuracy of DP ship are almost the same. 


\section{Conclusion}

In this paper, the effects of different wave spectra on dynamic positioning accuracy of DP ship is studied. The compared results show that different wave spectra have different effects on the calculations of DP ship's horizontal motion amplitude. It means that the dynamic positioning accuracy calculated based on different wave spectra would be discrepant. Besides, the effects of wave spectrum on dynamic positioning accuracy in each degree of freedom could be different. The change of DP ship's transverse, longitudinal displacement and yaw angle calculated by ISSC spectrum and Ochi-Hubble spectrum are highly consistent. The displacement amplitude of DP ship calculated by JONSWAP spectrum is smallest and the dynamic positioning accuracy is best in surge direction. Dynamic positioning accuracy calculated by Gaussian Swell is poor and have sufficient safety redundancy in surge direction. In sway and yaw direction, the dynamic positioning accuracy calculated by Gaussian Swell is good. The motion amplitude calculated by Torsethaugen spectrum is large and dynamic positioning accuracy is poor, which results in the calculation have sufficient safety redundancy. Therefore, in actual project practice, the wave spectra should be selected carefully when simulation is conducted for DP ship.

\section{ACKNOWLEDGMENTS}

This paper was financially supported by National Natural Science Foundation of China (Grant No. 51709118); China Postdoctoral Science Foundation (Grant No. 2017M612669); and the Fundamental Research Funds for the Central Universities (Grant No. 2017BQ089).

\section{REFERENCES}

[1] Chen, H. (2008). "Research on design of DP thruster system of deepwater semi-submersible platform," Shang Hai: Shanghai Jiao Tong University, 56,.

[2] Kijima, K., Furukawa, K.Y.(1997). "Ship maneuvering performance in waves," 3rd International Stability Workshop, 72.

[3] Surendran, S., Reddy, J.V.R.(2003). "Numerical simulation of ship stability for dynamic environment," Ocean Engineering, 30, 1305-1317. https://doi.org/10.1016/S0029-8018(02)00109-9.

[4] Wang, HW., Ma, G, Sun, LP, et al(2017). "Model test and coupled dynamic analysis of a deepwater FPSO with internal turret mooting system," Brodogradnja. 68(4), 43-55. https://doi.org/10.21278/brod68403.

[5] Ramalingam, V, Ramalingam, S, Srinivasan. R, et al(2017). "Parametric study on the hydrodynamic response of DSI polygonal shaped FPSO,” Brodogradnja. 68(2), 93-107. https://doi.org/10.21278/brod68207.

[6] Cai, F., Liu Q.(2007). "Study on numerical simulation of bi-spectrum wave," Shipbuilding of China, 48, 500-503.

[7] Isherwood, R.M.(1987). A Revised Parameterisation of the JONSWAP Spectrum. Applied Ocean Research, 9, No. 1 (January), 47-50. https://doi.org/10.1016/0141-1187(87)90030-7.

[8] Tucker, M.J.(1991). Waves in Ocean Engineering. Ellis Horwood Ltd. (Chichester).

[9] Ochi, M.K and Hubble, E.N, 1976. Six-parameter wave spectra, Proc 15th Coastal Engineering Conference, 301-328.

[10] Torsethaugen, K. and Haver, S.,(2004). Simplified double peak spectral model for ocean waves, Paper No. 2004-JSC-193, ISOPE 2004 Touson, France.

[11] Abyn, H , Islam, MR, Maimun, A, et al(2016). "Experimental study of motions of two floating offshore structure in waves,” Brodogradnja. 67(2), 1-13. https://doi.org/10.21278/brod67201.

[12] Fan, TH, Qiao, DS, Ou, JP(2014). "Dynamic effects of equivalent truncated mooring systems for a semisubmersible platform” Brodogradnja. 65(4), 35-51. 
[13] Sun, L., Zhu, J., Ai S., et al(2015). “Coupling time-domain analysis of dynamic positioning during S-lay operation," the Ocean Engineering, 33(4),1-9.

[14] Fossen, T. I. (1994), Guidance and Control of Ocean Vehicles. New York: Wiley.

[15] OrcaFlex Manual Version10.0a(2015). Orcina Ltd. http://www.orcina.com/SoftwareProducts/OrcaFlex/D ocumentation/OrcaFlex.pdf..

[16] Cummins, W.E.(1962). "The impulsive response function and ship motions. Symposium on Ship Theory,” Hamburg, Germany, Schiffstechnik, 9, 101-109.

[17] Liapis, S., Beck, R.F.(1985). "Seakeeping computations using time-domain analysis," Proc. Fourth International Conference on Numerical Ship Hydrodynamic, National Academy of Sciences, 34-56.

[18] Wang, D.,(2013). “Time domain coupling analysis of dynamic positioning of S-lay vessel,” Harbin: Harbin Engineering University, 1-71.

Submitted: 20.03.2017. Xinkuan Yan, PhD Student

Chaohe Chen, Professor

Accepted: $\quad$ 15.01.2018. Tianhui Fan, Assistant Professor, Corresponding Author, fanth@scut.edu.cn School of Civil Engineering and Transportation, South China University of Technology, Guangzhou, China 